\title{
The Impact of Cooking Classes on Food- Related Preferences, Attitudes, and Behaviors of School-Aged Children: A Systematic Review of the Evidence, 2003-2014
}

\author{
Derek Hersch, BS; Laura Perdue, MPH, RD; Teresa Ambroz, MPH, RD; \\ Jackie L. Boucher, MS, RD, CDE
}

Suggested citation for this article: Hersch D, Perdue L, Ambroz T, Boucher JL. The Impact of Cooking Classes on Food-Related Preferences, Attitudes, and Behaviors of School-Aged Children: A Systematic Review of the Evidence, 2003-2014. Prev Chronic Dis 2014;11:140267. DOI: http://dx.doi.org/10.5888/pcd11.140267.

\section{PEER REVIEWED}

\section{Abstract}

\section{Introduction}

Cooking programs have been used to promote healthful eating among people of all ages. This review assesses the evidence on childhood cooking programs and their association with changes in food-related preferences, attitudes, and behaviors of school-aged children.

\section{Methods}

We systematically searched PubMed, Ovid-Medline, and CINAHL (Cumulative Index to Nursing and Allied Health Literature) databases. We included primary research articles that involved cooking education programs for children and searched reference lists for eligible articles. Studies considered for review contained a hands-on cooking intervention; had participants aged 5 to 12 years; were published in a peer-reviewed journal on or after January 1, 2003; and were written in English. We used the Effective Public Health Practice Project Quality Assessment Tool for Quantitative Studies to rate the strength of each article and assess bias. The following information was extracted from each study: study design, sample size, location, duration, intervention components, data collection methods, and outcomes.

\begin{abstract}
Results
Eight studies met the inclusion criteria and used cooking education to influence children's food-related preferences, attitudes, and behaviors. Programs varied in duration, evaluation methods, and outcomes of interest. Self-reported food preparation skills, dietary intake, cooking confidence, fruit and vegetable preferences, attitudes toward food and cooking, and food-related knowledge were among the outcomes measured. Program exposure ranged from 2 sessions to regular instruction over 2 years, and the effect of cooking programs on children's food-related preferences, attitudes, and behaviors varied among the reviewed studies.
\end{abstract}

\section{Conclusions}

Findings suggest that cooking programs may positively influence children's food-related preferences, attitudes, and behaviors. However, because study measurements varied widely, determining best practices was difficult. Further research is needed to fill knowledge gaps on ideal program length, long-term effects, and usefulness of parent engagement, tasting lessons, and other intervention components.

\section{Introduction}

Since the 1980s, Americans have reduced the time they spend preparing and eating meals at home $(1,2)$. The cause of this cultural shift is unknown, although several suggested factors are increased proportion of parents in the labor force, food accessibility, and time constraints from longer working hours (3-5). These factors - along with a lack of basic cooking skills, healthful eating knowledge, or both - may influence families and, in turn, children, to increase their consumption of foods away from home (2). This behavior is problematic, because restaurant meals often lack 
adequate amounts of fruits and vegetables and are often caloriedense rather than nutrient-dense, which may result in poor diet quality and adverse health outcomes if such meals are consumed regularly (6-8).

Many interventions have attempted to increase consumption of and preferences for fruits and vegetables and influence other foodrelated preferences, attitudes, and behaviors among children (9). Although these efforts may be improving children's overall health, it is unknown what intervention component is effective at prompting the desired changes (10). Prompted by the shift away from home food preparation, researchers have begun to study cooking programs as a way to positively affect participants' food-related preferences, attitudes, and behaviors $(5,11,12)$.

Although evidence suggests that cooking programs are effective at improving food-related preferences, attitudes, and behaviors among adolescents and adults, their effect on children remains uncertain (13-17). A previous review of this topic identified only 4 studies, published between 1995 and January 2008, and concluded that evidence on the benefits of cooking programs was lacking (18). Despite null findings, cooking programs have been recommended by public health professionals to address the obesity epidemic $(3,5)$. This systematic review aims to assess the latest evidence concerning childhood cooking programs and their association with children's food-related preferences, attitudes, and behaviors; inform future efforts; and identify gaps in the literature.

\section{Methods}

\section{Data sources}

This systematic review was conducted using methods developed by Thomas et al for public health research (19). Three databases, PubMed, Ovid-Medline, and CINAHL (Cumulative Index to Nursing and Allied Health Literature), were searched for primary research articles published between January 2003 and March 2014 that involved cooking education programs. This timeframe was chosen to obtain a sample of recent programs. An exhaustive search was conducted using medical subject headings and keywords including cooking, education, and children. A reference list search was also performed via articles that met the inclusion criteria and relevant papers in the field.

\section{Study selection}

Studies were considered for review if they contained a cooking education intervention for children aged 5 to 12 years. This age range was selected on the basis of the average age of elementary school children in kindergarten through sixth grade; studies that included most children outside this age range were excluded. In- terventions were the only studies of interest; therefore, randomized controlled trials (RCTs) and quasi-experimental studies were the only types of studies accepted. To adequately assess program impact, the minimum sample size allowed was 10. Cooking education programs were defined as those that occurred in a community or school setting and involved food preparation lessons. Studies were required to adequately describe the cooking intervention and at least include the frequency of cooking activities and types of recipes made. Those studies that only evaluated a previously conducted intervention or did not contain hands-on cooking by children were also excluded.

Study titles and abstracts retrieved from the initial database searches were independently screened by 2 authors to determine suitability for review. Author information and journal titles were not concealed from the reviewers. Articles with abstracts containing information that conflicted with at least 1 of the inclusion criteria were excluded. Full-text articles of abstracts meeting all of the inclusion criteria were obtained through the University of Minnesota library. Two review authors independently inspected each article to determine aptness for review inclusion. Final decisions for inclusion and exclusion were made by agreement among all listed authors (Figure).

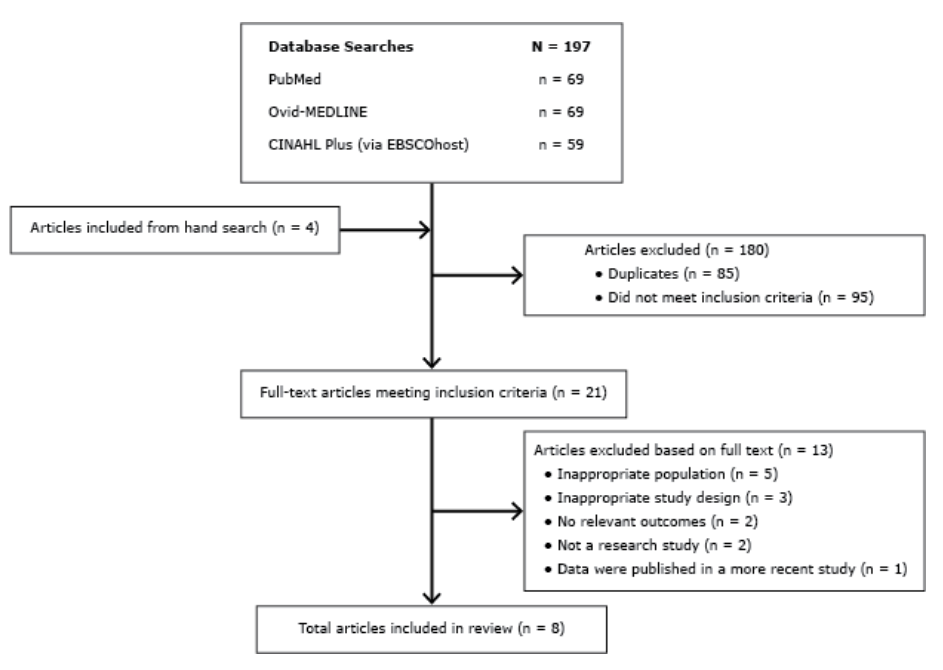

Figure. Flow diagram depicting systematic literature search of cooking education programs for children aged 5 to 12 years published between 2003 and 2014. Abbreviation: CINAHL, Cumulative Index to Nursing and Allied Health Literature.

\section{Data extraction}

Study data were independently obtained by 2 authors who were not blind to the author information or journal titles. The following information was extracted from each study: study design, sample

\footnotetext{
The opinions expressed by authors contributing to this journal do not necessarily reflect the opinions of the U.S. Department of Health and Human Services, the Public Health Service, the Centers for Disease Control and Prevention, or the authors' affiliated institutions.
} 
size, location, duration, intervention components, data collection methods, and outcomes. Study authors were not contacted, and only published information was extracted for this review. Quality assessments were independently conducted for each article by 2 reviewers. The Effective Public Health Practice Project (EPHPP) Quality Assessment Tool for Quantitative Studies was used to rate each article according to selection bias, study design, control of confounders, blinding, data collection methods, and withdrawal and drop-out rates (19). This assessment tool has been validated and recommended for use in systematic reviews of public health interventions to rate the methodological quality and validity of RCTs and quasi-experimental and uncontrolled studies (19-22). Study components were rated using the EPHPP tool as strong, moderate, or weak. Studies were rated strong overall if none of the components were rated weak, moderate overall if 1 component was rated weak, or weak overall if 2 or more components were rated weak. Because of the low number of published articles on this topic, articles rated as weak, moderate, or strong were reviewed. Institutional review board approval was not sought or required for this study, according to US Department of Health and Human Services guidelines (23).

\section{Results}

\section{Overview of included studies}

Eight articles met the inclusion criteria and were published between January 2003 and March 2014, in 7 different journals (Table 1) (24-31). Recruitment for all included studies occurred in the elementary or primary school setting; sample sizes ranged from 44 (29) to 1,230 (27). Six (24-27,30,31) of the interventions were conducted during the school day and integrated into the classroom curriculum, 1 (28) took place in an after-school program and was taught at a community garden, and the other study (29) occurred in the evening at a community center. Among 7 of the 8 studies, the median number of structured sessions was 10 (range, 2-12 sessions) (24-29,31). The final study, which was integrated into the participating schools' curriculums, occurred on a weekly basis while school was in session for 2-and-a-half years, but the actual number of sessions was not reported (30). Duration of lessons were reported in 5 of the 8 studies, with a median time of 90 minutes (range, 90-120 minutes) (26-30). Three of the studies engaged parents, either through separate lessons $(28,29)$ or a newsletter that was sent home (31).

The outcomes of interest and evaluation methods used varied (Table 2). Two interventions evaluated participants' willingness to try new foods $(30,31) ; 4$ studies measured food preparation skills and cooking confidence $(24,26,27,29)$. Among the 5 studies that conducted preintervention and postintervention dietary assessments, 2 used 24-hour dietary recalls $(25,29), 1$ used a food frequency questionnaire (28), 1 used both methods (31), and 1 (24) used selfreported consumption of selected vegetables. Fruit and vegetable preference was also measured in 3 studies using a qualitative scale (25-27). Anthropometrics were obtained in 2 of the interventions, with body mass index (BMI) as an outcome of interest $(28,29) ; 1$ study (28) also measured waist circumference, blood pressure, and total body fat.

Using the EPHPP tool (19), 2 (26,27) articles were considered strong in quality, $3(24,28,29)$ moderate in quality, and 3 $(25,30,31)$ weak in quality (Table 1$)$. The selection bias and confounding components of the assessment resulted in the most weak ratings, with 3 studies each. Data collection methods and withdrawals and drop-outs had the most strong ratings, with 5 studies qualifying. Few similarities existed between studies' quality ratings, except for Caraher et al (24)and Davis et al (28), which had identical ratings.

\section{Effects of interventions}

Outcomes of the included studies are summarized in Table 2. The 2 studies that assessed children's willingness to try new foods found an increase postintervention in the intervention group compared with baseline (30) or a control group (31). Children were also more willing to try new foods if they had cooked or had grown it (30). When parents were asked about their child's willingness to always try new foods, a nonsignificant increase was observed (30). Caraher et al qualitatively measured students' preference for the 5 vegetables used in the class recipe (24). No significant change was observed in the control group's responses, but a significant increase was observed among those in the intervention group. Attitudes toward cooking and food were measured by selfreport questionnaires in both studies conducted by CunninghamSabo and Lohse (26,27). Among fourth-graders in Colorado, changes in attitudes toward cooking and food were significantly greater among the intervention group than among the control group (26). Among children in New Mexico, cooking attitudes did not significantly change, regardless of the intervention group (27).

Food preparation skills and cooking confidence were determined in 2 studies on the basis of participants' reported ability to cut up fruits and vegetables, follow a recipe, and measure ingredients, among several other food preparation actions $(24,29)$. Caraher et al observed a significant increase in cooking confidence scores (on a scale from 1 to 4 ) among both the intervention and control groups from baseline to follow-up (24). Fulkerson et al compared the food preparation skills of children and parents in intervention

The opinions expressed by authors contributing to this journal do not necessarily reflect the opinions of the U.S. Department of Health and Human Services, the Public Health Service, the Centers for Disease Control and Prevention, or the authors' affiliated institutions. 
and control groups; they found a significant difference among the children but not among the parents (29). Cunningham-Sabo et al also measured cooking self-efficacy and found significant improvements among fourth graders in Colorado (26) and New Mexico (27).

Among the 4 studies that measured children's preintervention and postintervention daily servings of fruits and vegetables, 1 (25) found significant increases from baseline in both fruit and vegetable consumption and 1 (31) found a significant increase from baseline for fruit consumption only. Nonsignificant increases from baseline were observed in the 2 other studies $(28,29)$. Caraher et al (24) used self-reported consumption of selected vegetables as a proxy for overall vegetable consumption. Participants were asked preintervention and postintervention if they had consumed any of the 5 vegetables at least once over the past week. Although no difference was observed in the control group at follow-up, the proportion who reported eating 1 or more of the vegetables in the intervention group significantly increased from baseline. Two studies $(26,27)$ out of 3 that measured children's preferences for fruits, vegetables, or both found a significant increase from preintervention to postintervention; the third did not compare preintervention with postintervention and used the comparison only as an adjustor in the analysis (25).

Among the studies that measured physical characteristics, findings were mixed. Two interventions $(28,29)$ found nonsignificant changes in BMI from baseline to follow-up, and 1 (28) found no change in total body fat percentage from baseline to follow-up. However, Davis et al observed a significant decrease in BMI from baseline to follow-up among overweight and obese participants in the intervention group compared with overweight and obese participants in the control group (28). Improvements in diastolic blood pressure from baseline to follow-up were significantly different between treatment and control groups (28).

\section{Study quality}

Overall study quality, as measured by the EPHPP tool (19), of the included studies ranged from weak to strong. Three studies (29-31) likely are subject to selection bias; samples were selected for convenience or participation was self-selected. Regarding study design, $2(26,29)$ were RCTs, $4(24,27,28,31)$ were quasi-experimental with control groups, and 1 (25) randomly selected individuals for the intervention but did not have a control group. Three studies $(24,25,28)$ lacked appropriate consideration for confounders. Blinding was not mentioned in any of the included studies, and whether participants' responses were influenced by knowledge of the research aims is unclear. Data collection methods and tools were reported to be valid and reliable in 4 studies $(24,26-28)$, reliable in 1 (29), with no information given in the re- maining 2 (30,31). Five studies (24,26-29) reported participation rates greater than $80 \%, 2(30,31)$ had rates between $60 \%$ and $79 \%$, and 1 (25) did not report participation rates.

\section{Discussion}

Given the rise in childhood obesity and known cultural shifts away from cooking, a review of cooking programs targeting elementary school children was conducted to understand program design and outcomes and to inform research gaps. Similar to findings of previous systematic and informal reviews of the literature, we found limited scientific articles written about the effectiveness of cooking interventions on children's food-related preferences, attitudes, and behaviors $(5,18)$.

Analyzing studies with intervention lengths ranging from 2 sessions to regular instruction over 2 years and with diverse outcome measurements makes determining best practices difficult. Data collection methods also differed greatly among studies; only 2 took physical measurements $(28,29)$, and fruit and vegetable consumption was estimated predominantly by self-report or parent report. Because these collection methods vary in their reliability, generalizing the reviewed programs' effectiveness at influencing food-related preferences, attitudes, and behaviors is challenging. The availability of tools to effectively measure behavioral and dietary characteristics, especially among children, is a limitation in the field of nutrition $(32,33)$.

Given that only $2(26,27)$ of the studies reviewed were considered strong according to EPHPP criteria, there appears to be a lack of high-quality intervention studies on childhood cooking programs. The literature lacks an adequate number of studies that effectively randomize participants to treatment and control groups. In most cases, this lack of randomization results from the availability of schools that are willing and able to accommodate a cooking program. Inadequate funding may also be an issue, given that randomization of schools and stronger study designs also require significantly more resources. Strict curriculum requirements may also affect study design and researchers' ability to implement cooking interventions in schools; many schools do not have the time to include additional lessons, resulting in a small pool of possible schools and, in turn, participants who can be adequately randomized. As a result, researchers may not have been able to obtain a representative sample.

Despite various differences in delivery, each program had a significant effect on 1 or more of its participants' food-related preferences, attitudes, and behaviors, although this finding could be attributed to publication bias. In studies that measured it, children's willingness to try fruits and vegetables significantly increased after

\footnotetext{
The opinions expressed by authors contributing to this journal do not necessarily reflect the opinions of the U.S. Department of Health and Human Services, the Public Health Service, the Centers for Disease Control and Prevention, or the authors' affiliated institutions.
} 
the cooking intervention $(24,30,31)$. Furthermore, participants' fruit and vegetable consumption, as reported by their parents, also significantly increased $(24,31)$. In one case, these improvements were observed after only 2 cooking lessons (24). Although these short-term improvements are promising from a feasibility standpoint, repeated exposures are suggested to increase children's preference for fruits and vegetables (34-36). Longer programs can incorporate more cooking skills, provide in-depth nutrition education, and better incorporate a culture of wellness into the school, the community, or both. It is also unclear whether participants benefited from having their parents involved in the cooking classes. None of the studies measured the impact that the programs had on parents' food-related preferences, attitudes, and behaviors, although cooking programs for adults have had a modest impact on diet quality and food preferences (17).

Although some programs had a significant short-term impact on children's food-related preferences, attitudes, and behaviors, the long-term sustainability of these changes is unknown. One study conducted follow-up surveys 6 months postintervention, but the results were not published (29). As more evidence suggests that childhood weight status is a good predictor of adult weight status, long-term evaluations that measure sustainability are needed to identify effective intervention strategies. Given that food-related preferences, attitudes, and behaviors can change dramatically throughout grade school, teaching sustainable healthful habits at a young age could have dramatic implications (37). However, the literature lacks substantial evidence about whether healthful habits taught at a young age are maintained.

This systematic review has some limitations. Efforts were made to capture all available published studies related to the aim of the review. However, selection and publication bias, inherent to the research modality, may be present. Also, if articles did not fully describe the cooking interventions, they were excluded without contacting authors; therefore, an article could have met the inclusion criteria if more information had been provided.

Our findings indicate that cooking education programs may be a promising tool for promoting positive changes in children's foodrelated preferences, attitudes, and behaviors. Although no best practices or consistent themes were found among the successful interventions, gaps in the evidence were identified to inform future studies. What components are necessary for an effective program is unclear. Several design elements of cooking programs also require further research: where programs should occur, the ideal number of exposures, whether nutrition education should be paired with cooking lessons, the role of parent involvement, and the usefulness of tastings and gardening activities. In terms of program outcomes, more evidence is needed to determine whether changes in food choices are occurring as a result of cooking interventions and whether changes are sustained through childhood and adolescence. Future studies should address these gaps through controlled trials that measure both quantitative and qualitative effects; ideally they should be conducted in various environments such as schools, community centers, and the home.

\section{Acknowledgments}

This work was conducted both as part of an internship and paid assistantship by Allina Health and the Minneapolis Heart Institute Foundation.

\section{Author Information}

Corresponding Author: Derek Hersch, BS, Minneapolis Heart Institute Foundation, 920 East 28th St, Suite 100, Minneapolis, MN 55407. Telephone:612-863-6016. E-mail: DHersch@mhif.org.

Author Affiliations: Laura Perdue, University of Minnesota Extension Regional Center, St. Cloud, Minnesota; Teresa Ambroz, Jackie L. Boucher, Minneapolis Heart Institute Foundation, Minneapolis, Minnesota.

\section{References}

1. Drewnowski A, Rehm CD. Energy intakes of US children and adults by food purchase location and by specific food source. Nutr J 2013;12(1):59.

2. Smith LP, Ng SW, Popkin BM. Trends in US home food preparation and consumption: analysis of national nutrition surveys and time use studies from 1965-1966 to 2007-2008. Nutr J 2013;12(1):45.

3. Condrasky MD, Hegler M. How culinary nutrition can save the health of a nation. J Ext 2010;48(2):2COM1.

4. Michaud P, Condrasky M, Griffin S.Review and application of current literature related to culinary programs for nutrition educators. Top Clin Nutr 2007;22(4).

5. Nelson S, Corbin M, Nickols-Richardson SM. A call for culinary skills education in childhood obesity-prevention interventions: current status and peer influences. J Acad Nutr Diet 2013;113(8):1031-6.

6. Krebs-Smith SM, Guenther PM, Subar AF, Kirkpatrick SI, Dodd KW. Americans do not meet federal dietary recommendations. J Nutr 2010;140(10):1832-8. 
7. Powell LM, Nguyen BT. Fast-food and full-service restaurant consumption among children and adolescents: effect on energy, beverage, and nutrient intake. JAMA Pediatr 2013; 167(1):14-20.

8. Jaworowska A, Blackham T, Davies IG, Stevenson L. Nutritional challenges and health implications of takeaway and fast food. Nutr Rev 2013;71(5):310-8.

9. Ganann R, Fitzpatrick-Lewis D, Ciliska D, Peirson L. Community-based interventions for enhancing access to or consumption of fruit and vegetables among five to 18-year olds: a scoping review. BMC Public Health 2012;12(1):711.

10. Waters E, de Silva-Sanigorski A, Hall BJ, Brown T, Campbell $\mathrm{KJ}$, Gao Y, et al. Interventions for preventing obesity in children. Cochrane Database Syst Rev 2011;(12):CD001871.

11. Brown BJ, Hermann JR. Cooking classes increase fruit and vegetable intake and food safety behaviors in youth and adults. J Nutr Educ Behav 2005;37(2):104-5.

12. Hoelscher DM, Kirk S, Ritchie L, Cunningham-Sabo L. Position of the Academy of Nutrition and Dietetics: interventions for the prevention and treatment of pediatric overweight and obesity. J Acad Nutr Diet 2013; 113(10):1375-94.

13. Larson NI, Perry CL, Story M, Neumark-Sztainer D. Food preparation by young adults is associated with better diet quality. J Am Diet Assoc 2006;106(12):2001-7.

14. Condrasky M, Graham K, Kamp J. Cooking with a Chef: an innovative program to improve mealtime practices and eating behaviors of caregivers of preschool children. J Nutr Educ Behav 2006;38(5):324-5.

15. Wrieden WL, Anderson AS, Longbottom PJ, Valentine K, Stead M, Caraher M, et al. The impact of a community-based food skills intervention on cooking confidence, food preparation methods and dietary choices - an exploratory trial. Public Health Nutr 2007;10(2):203-11.

16. Thomas HM, Irwin JD. Cook It Up! A community-based cooking program for at-risk youth: overview of a food literacy intervention. BMC Res Notes 2011;4(1):495.

17. Reicks M, Trofholz AC, Stang JS, Laska MN. Impact of cooking and home food preparation interventions among adults: outcomes and implications for future programs. J Nutr Educ Behav 2014;46(4):259-76.

18. Seeley A, Wu M, Caraher M. Should we teach cooking in schools? A systematic review of the literature of school-based cooking interventions. J Home Econ Inst Aust 2010; 17(1):10-9.

19. Thomas BH, Ciliska D, Dobbins M, Micucci S. A process for systematically reviewing the literature: providing the research evidence for public health nursing interventions. Worldviews Evid Based Nurs 2004;1(3):176-84.
20. Deeks JJ, Dinnes J, D’Amico R, Sowden J, Sakarovitch C, Song $\mathrm{F}$, et al. Evaluating non-randomised intervention studies. Health Technol Assess 2003;7(27):iii-x, 1-173.

21. Jackson N, Waters E. Criteria for the systematic review of health promotion and public health interventions. Health Promot Int 2005;20(4):367-74.

22. Armijo-Olivo S, Stiles CR, Hagen N, Biondo PD, Cummings GG. Assessment of study quality for systematic reviews: a comparison of the Cochrane Collaboration Risk of Bias Tool and the Effective Public Health Practice Project Quality Assessment Tool: methodological research. J Eval Clin Pract 2012;18(1):12-8.

23. Human subject regulations decision charts. Office for Human Research Protections. http://www.hhs.gov/ohrp/policy/ checklists/decisioncharts.html\#c1. Accessed July 10, 2013.

24. Caraher M, Seeley A, Wu M, Lloyd S. When chefs adopt a school? An evaluation of a cooking intervention in English primary schools. Appetite 2013;62:50-9.

25. Cullen KW, Watson KB, Zakeri I, Baranowski T, Baranowski $\mathrm{JH}$. Achieving fruit, juice, and vegetable recipe preparation goals influences consumption by 4 th grade students. Int $\mathrm{J}$ Behav Nutr Phys Act 2007;4:28.

26. Cunningham-Sabo L, Lohse B. Cooking with kids positively affects fourth graders' vegetable preferences and attitudes and self-efficacy for food and cooking. Child Obes 2013; 9(6):549-56.

27. Cunningham-Sabo L, Lohse B. Impact of a school-based cooking curriculum for fourth-grade students on attitudes and behaviors is influenced by gender and prior cooking experience. J Nutr Educ Behav 2014;46(2):110-20.

28. Davis JN, Ventura EE, Cook LT, Gyllenhammer LE, Gatto NMLA. Sprouts: a gardening, nutrition, and cooking intervention for Latino youth improves diet and reduces obesity. J Am Diet Assoc 2011;111(8):1224-30.

29. Fulkerson JA, Rydell S, Kubik MY, Lytle L, Boutelle K, Story $\mathrm{M}$, et al. Healthy Home Offerings via the Mealtime Environment (HOME): feasibility, acceptability, and outcomes of a pilot study. Obesity (Silver Spring) 2010;18(1):S69-74.

30. Gibbs L, Staiger PK, Johnson B, Block K, Macfarlane S, Gold L, et al. Expanding children's food experiences: the impact of a school-based kitchen garden program. J Nutr Educ Behav 2013;45(2):137-46.

31. Quinn L, Horacek T, Castle J. The impact of Cookshop on the dietary habits and attitudes of fifth graders. Topics Clin Nutr 2003;18(1):42-8.

32. Burrows TL, Martin RJ, Collins CE. A systematic review of the validity of dietary assessment methods in children when compared with the method of doubly labeled water. J Am Diet Assoc 2010;110(10):1501-10.

\footnotetext{
The opinions expressed by authors contributing to this journal do not necessarily reflect the opinions of the U.S. Department of Health and Human Services, the Public Health Service, the Centers for Disease Control and Prevention, or the authors' affiliated institutions.
} 
33. Burrows T, Golley RK, Khambalia A, McNaughton SA, Magarey A, Rosenkranz RR, et al. The quality of dietary intake methodology and reporting in child and adolescent obesity intervention trials: a systematic review. Obes Rev 2012; 13(12):1125-38.

34. Wardle J, Herrera M-L, Cooke L, Gibson EL. Modifying children's food preferences: the effects of exposure and reward on acceptance of an unfamiliar vegetable. Eur J Clin Nutr 2003;57(2):341-8.

35. O'Connell ML, Henderson KE, Luedicke J, Schwartz MB. Repeated exposure in a natural setting: a preschool intervention to increase vegetable consumption. J Acad Nutr Diet 2012;112(2):230-4.

36. Noradilah MJ, Zahara AM. Acceptance of a test vegetable after repeated exposures among preschoolers. Malays J Nutr 2012; 18(1):67-75.

37. Lytle LA, Seifert S, Greenstein J, McGovern P. How do children's eating patterns and food choices change over time? Results from a cohort study. Am J Health Promot 2000; 14(4):222-8. 


\section{Tables}

Table 1. Characteristics of Included Studies that Involved Primary School-Aged Children and Contained a Cooking Component $(\mathrm{n}=$ 8)

\begin{tabular}{|c|c|c|c|c|c|}
\hline Study Purpose & Study Design & $\begin{array}{l}\text { EPHPP } \\
\text { Rating }\end{array}$ & Sample Size & Duration & $\begin{array}{l}\text { Intervention } \\
\text { Components }\end{array}$ \\
\hline \multicolumn{6}{|l|}{ Caraher et al $2013(24)$} \\
\hline $\begin{array}{l}\text { Determine the effectiveness of an in-school } \\
\text { cooking program that uses chefs as } \\
\text { instructors }\end{array}$ & $\begin{array}{l}2 \text { group; quasi- } \\
\text { experimental; } \\
\text { pre-post } \\
\text { assessment }\end{array}$ & Moderate & $\begin{array}{l}\text { Intervention group: } n \\
=86 ; \text { control group: } n \\
=83\end{array}$ & 2 sessions & Cooking lessons \\
\hline \multicolumn{6}{|l|}{ Cullen et al 2007 (25) } \\
\hline $\begin{array}{l}\text { Increase fruit and vegetable consumption } \\
\text { through a multimedia-based food } \\
\text { preparation and eating behavior curriculum }\end{array}$ & $\begin{array}{l}\text { Randomized; } 1 \\
\text { group; } \\
\text { pre-post } \\
\text { assessment }\end{array}$ & Weak & $\begin{array}{l}\text { Intervention group: } \mathrm{n} \\
=671\end{array}$ & 10 sessions over 5 weeks & $\begin{array}{l}\text { Cooking lessons; } \\
\text { nutrition } \\
\text { education }\end{array}$ \\
\hline \multicolumn{6}{|l|}{ Cunningham-Sabo and Lohse 2013 (26) } \\
\hline $\begin{array}{l}\text { Determine the impact of a cooking and } \\
\text { tasting program on children's cooking } \\
\text { attitudes, cooking self-efficacy, and fruit } \\
\text { and vegetable preferences }\end{array}$ & $\begin{array}{l}\text { Randomized; } 2 \\
\text { group; } \\
\text { pre-post } \\
\text { assessment }\end{array}$ & Strong & $\begin{array}{l}\text { Intervention group: } n \\
=137 ; \text { control group: } \\
n=120\end{array}$ & $\begin{array}{l}3 \text { two-hour cooking classes } \\
\text { and } 3 \text { one-hour tasting } \\
\text { sessions over } 1 \text { school } \\
\text { semester }\end{array}$ & $\begin{array}{l}\text { Cooking lessons; } \\
\text { tasting activities }\end{array}$ \\
\hline \multicolumn{6}{|l|}{ Cunningham-Sabo and Lohse 2014 (27) } \\
\hline $\begin{array}{l}\text { Compare the impact on children's cooking } \\
\text { attitudes, cooking self-efficacy, and fruit } \\
\text { and vegetable preferences between a } \\
\text { cooking and tasting program, a tasting-only } \\
\text { program, and a control group }\end{array}$ & $\begin{array}{l}3 \text { group; quasi- } \\
\text { experimental; } \\
\text { pre-post } \\
\text { assessment }\end{array}$ & Strong & $\begin{array}{l}\text { Cooking and tasting } \\
\text { group: } \mathrm{n}=539 ; \\
\text { tasting group: } \mathrm{n}= \\
294 ; \text { control group: } \mathrm{n} \\
=397\end{array}$ & $\begin{array}{l}5 \text { two-hour cooking lessons } \\
\text { and } 5 \text { one-hour tasting } \\
\text { lessons during a 9-month } \\
\text { school year }\end{array}$ & $\begin{array}{l}\text { Cooking lessons; } \\
\text { tasting activities }\end{array}$ \\
\hline \multicolumn{6}{|l|}{ Davis et al $2011(28)$} \\
\hline $\begin{array}{l}\text { Determine the effects of a culturally } \\
\text { focused, 12-week gardening and cooking } \\
\text { program on dietary intake and health } \\
\text { outcomes among predominantly Hispanic, } \\
\text { fourth- and fifth-grade students }\end{array}$ & $\begin{array}{l}2 \text { group; quasi- } \\
\text { experimental; } \\
\text { pre-post } \\
\text { assessment }\end{array}$ & Moderate & $\begin{array}{l}\text { Intervention group: } \mathrm{n} \\
=34 ; \text { control group: } \mathrm{n} \\
=70\end{array}$ & $\begin{array}{l}\text { Twelve 45-minute nutrition } \\
\text { and cooking lessons and } \\
\text { twelve 45-minute gardening } \\
\text { lessons over a 12-week } \\
\text { period }\end{array}$ & $\begin{array}{l}\text { Cooking lessons; } \\
\text { nutrition } \\
\text { education; } \\
\text { gardening lessons }\end{array}$ \\
\hline \multicolumn{6}{|l|}{ Fulkerson et al $2010(29)$} \\
\hline $\begin{array}{l}\text { Pilot a parent-child nutrition education } \\
\text { program to increase family dinner } \\
\text { frequency, parent self-efficacy in preparing } \\
\text { healthy meals and child food preparation } \\
\text { skills }\end{array}$ & $\begin{array}{l}2 \text { group; } \\
\text { experimental; } \\
\text { post } \\
\text { assessment }\end{array}$ & Moderate & $\begin{array}{l}\text { Intervention group: } n \\
=22 ; \text { control group: } n \\
=22\end{array}$ & $\begin{array}{l}\text { Five 90-minute sessions } \\
\text { over a } 10 \text {-week period }\end{array}$ & $\begin{array}{l}\text { Cooking lessons; } \\
\text { nutrition } \\
\text { education; tasting } \\
\text { activities; group } \\
\text { meals }\end{array}$ \\
\hline \multicolumn{6}{|l|}{ Gibbs et al $2013(30)$} \\
\hline $\begin{array}{l}\text { Determine the effectiveness of an in-school } \\
\text { nutrition and gardening program on } \\
\text { elementary school children's willingness to } \\
\text { try new foods }\end{array}$ & $\begin{array}{l}2 \text { group; quasi- } \\
\text { experimental; } \\
\text { pre-post } \\
\text { assessment }\end{array}$ & Weak & $\begin{array}{l}\text { Intervention group: } n \\
=463 ; \text { control group: } \\
n=280\end{array}$ & $\begin{array}{l}\text { Weekly } 45 \text {-minute garden } \\
\text { and } 90-\text { minute cooking } \\
\text { classes, while school was in } \\
\text { session, for } 2.5 \text { years }\end{array}$ & $\begin{array}{l}\text { Cooking lessons; } \\
\text { gardening lessons }\end{array}$ \\
\hline \multicolumn{6}{|l|}{ Quinn et al 2003 (31) } \\
\hline $\begin{array}{l}\text { Improve attitudes toward and increase the } \\
\text { fruit and vegetable consumption of fifth- } \\
\text { grade students }\end{array}$ & $\begin{array}{l}2 \text { group; quasi- } \\
\text { experimental; } \\
\text { pre-post } \\
\text { assessment }\end{array}$ & Weak & $\begin{array}{l}\text { Intervention group: } n \\
=81 ; \text { control group: } n \\
=68\end{array}$ & 11 sessions & $\begin{array}{l}\text { Cooking lessons; } \\
\text { nutrition } \\
\text { education }\end{array}$ \\
\hline
\end{tabular}

Abbreviation: EPHPP, Effective Public Health Practice Project.

The opinions expressed by authors contributing to this journal do not necessarily reflect the opinions of the U.S. Department of Health and Human Services, the Public Health Service, the Centers for Disease Control and Prevention, or the authors' affiliated institutions.

8 Centers for Disease Control and Prevention • www.cdc.gov/pcd/issues/2014/14_0267.htm 
Table 2. Outcomes of Interest, Evaluation Methods, and Major Findings of Included Studies ( $n=8$ )

\begin{tabular}{|l|}
\hline Outcome of Interest and Evaluation Method \\
\hline Caraher et al $\mathbf{2 0 1 3}$ (24) \\
\hline $\begin{array}{l}\text { Cooking confidence, vegetable consumption, and confidence in asking } \\
\text { for favorite vegetable assessed by child questionnaire }\end{array}$
\end{tabular}

Major Findings

for favorite vegetable assessed by child questionnaire

Increase in cooking confidence among the intervention and control groups; increase in vegetable consumption in the intervention group; confidence to ask parents for pasta salad ingredients increased in the intervention group

\section{Cullen et al 2007 (25)}

Fruit and vegetable consumption assessed by 24-h dietary recall; fruit and vegetable preferences and self-efficacy for eating fruits and vegetables assessed by child questionnaire
An increase of 1 combined serving of fruit, 100\% fruit juice, and vegetables was observed for participants who had the highest baseline consumption of fruits and vegetables and completed 2 or 3 goals; increase in vegetable consumption was observed among those with the highest baseline consumption that completed 0 preparation goals or 1 preparation goal

\section{Cunningham-Sabo and Lohse 2013 (26)}

Fruit and vegetable preferences, attitudes toward cooking, and cooking self-efficacy assessed by child questionnaire

\section{Cunningham-Sabo and Lohse 2014 (27)}

Fruit and vegetable preferences, attitudes toward cooking, and cooking self-efficacy assessed by child questionnaire.

\section{Davis et al 2011 (28)}

Overall health measured by BMI, total body fat, waist circumference, and blood pressure; dietary intake assessed by 41 -item food frequency questionnaire

Participants in the treatment group had higher fruit preference scores, vegetable preference scores, and attitudes toward food and cooking and cooking self-efficacy than participants in the control group; baseline to follow-up changes were also greater in the treatment group than in the control group for vegetable preference scores, attitudes toward cooking, and food and cooking self-efficacy

Participants in the cooking and tasting intervention had the highest increases in cooking self-efficacy; changes in fruit and vegetable preferences were greater among participants in the cooking and tasting group than among participants in the control group; changes in vegetable preferences were also greater among participants in both intervention groups than among those in the control groups

Dietary fiber intake increased by $22 \%$ among participants in the intervention group, and dietary fiber intake decreased by $12 \%$ among participants in the control group; diastolic blood pressure decreased more among participants in the intervention group than among those in the control group; overweight participants in the intervention group gained less weight and had a greater improvement in BMI than overweight participants in the control group

\section{Fulkerson et al 2010 (29)}

Frequency of family dinners, food sources, parental self-efficacy regarding healthful changes at home and child's food preparation skill assessed by parent questionnaire; food preparation skills assessed by child questionnaire; obesity status measured by BMI; home food availability assessed by home food inventory tool; family meal quality assessed by brief mealtime screener tool; dietary intake assessed by 24 hour recall

\section{Gibbs et al 2013 (30)}

Willingness to try new foods assessed by parent and child questionnaires; food choices and ability to describe foods assessed by child questionnaire

Children in the intervention group rated their food preparation skills higher than did participants in the control group; by parent report, child participation in meal preparation was higher in the intervention group than it was among children in the control group

\section{Quinn et al 2003 (31)}

Dietary intake assessed by 7 -item fruit and vegetable food frequency questionnaire and 24-hour dietary recall; food-related knowledge,
Children's willingness to try a new food if they had never tried it, cooked it, or grown it increased more among participants in the intervention schools than among participants in the control schools

Participants in the intervention group consumed more fiber than did participants in the control group; participants in the intervention group

Abbreviation: BMI, body mass index.

(continued on next page)

The opinions expressed by authors contributing to this journal do not necessarily reflect the opinions of the U.S. Department of Health and Human Services, the Public Health Service, the Centers for Disease Control and Prevention, or the authors' affiliated institutions. 
(continued)

Table 2. Outcomes of Interest, Evaluation Methods, and Major Findings of Included Studies $(n=8)$

\begin{tabular}{|l|l|}
\hline Outcome of Interest and Evaluation Method & \multicolumn{1}{c}{ Major Findings } \\
\hline $\begin{array}{l}\text { attitudes toward food, willingness to try new vegetables, exposure to } \\
\text { healthful foods, and eating habits assessed by child questionnaire; } \\
\text { perception of children's attitudes and eating habits and household } \\
\text { cooking and purchasing habits assessed by parent questionnaire }\end{array}$ & $\begin{array}{l}\text { increased dietary folate, fruit servings, and milk servings; students in } \\
\text { the intervention group were more willing to try new vegetables than } \\
\text { were children in the control group; 44\% of parents reported an } \\
\text { increase in the amount of fruit and vegetables their children were } \\
\text { eating since the program was completed }\end{array}$ \\
\hline
\end{tabular}

Abbreviation: BMI, body mass index.

The opinions expressed by authors contributing to this journal do not necessarily reflect the opinions of the U.S. Department of Health and Human Services, the Public Health Service, the Centers for Disease Control and Prevention, or the authors' affiliated institutions. 